\title{
Study of Mutual Improvement of Completed Weathered Phyllite and Red Clay Based on Neutralization Effects of Swelling and Shrinkage Deformation
}

\author{
Xiushao Zhao ${ }^{1}$, Qijing Yang ${ }^{1,2, *}$, Jianglong Rao ${ }^{1}$, Daxin Geng ${ }^{1}$ and Zhouyong $\operatorname{Tan}^{1}$ \\ ${ }^{1}$ Engineering Research \& Development Centre for Underground Technology of Jiangxi Province, East China Jiaotong University, \\ Nanchang, 330013, China \\ ${ }^{2}$ Arcadis AustraliaPacific Pty Ltd., Sydney, Australia \\ *Corresponding Author: Qijing Yang. Email: jimyang828@hotmail.com
}

Received: 19 January 2021 Accepted: 19 February 2021

\begin{abstract}
Completely weathered phyllite (CWP) soil is a kind of special soil with high swell potential, while red clay is a special soil with high shrinkage. This means that these two kinds of special soils are usually not suitable for direct use as subgrade fill. To reduce the swell index of the CWP soil and the shrinkage of red clay at the same time, it was proposed to blend the CWP soil with red clay to improve their basic characteristics. A series of swell index tests and dry-wet cycle tests of the blended soils have been carried out at varying blending ratios, compaction coefficients and moisture contents. The test results show that the free swell index of the blended soil decreases with the increase of red clay, moisture content and compaction coefficient, respectively. The fissure density of the blended soil first decreases and then increases with the blending ratio, with the lowest being zero when the blending ratio is ranging from $20 \%$ to $40 \%$. Through particle microscopic analysis and elemental composition analysis, it is found that the neutralization effect, the dilution effect of swell minerals, and the partition effect of coarse particles play an important role in restraining expansion and shrinkage deformation of the blended soil. Based on the liquid limit requirement of Chinese Railway Design Code (TB 10001-2016), the optimal blending ratio of red clay has been proposed to be $50 \%$. Compared with the CWP soil, the free load swell index of the blended soil is reduced by $45.0 \%$ and the fissure density is reduced by $99.3 \%$ compared with that of red clay. Therefore, it is feasible to improve the CWP soil by blending it with red clay at an optimal ratio of $50 \%$ by using the neutralization effect of the expansion of CWP and shrinkage of red clay.
\end{abstract}

\section{KEYWORDS}

Completely weathered phyllite; red clay; swell index; fissure density; neutralization effect; blending improvement method

\section{Introduction}

The completed weathered phyllite (CWP) soil and red clay are widely distributed in south China, including Jiangxi Province and Zhejiang Province. The CWP soil is the product of complete weathering of phyllite and has a high level of expansibility when soaking [1-3]. Moisture content and mineral components have significant effects on physical and mechanical properties of phyllite [4,5]. X-ray fluorescence (XRF), X-ray diffraction (XRD), transmission electron microscopy (TEM) and scanning electron microscopy (SEM) are often used to detect the mineral components or micro-structure of phyllite [6].

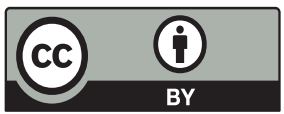

This work is licensed under a Creative Commons Attribution 4.0 International License, which permits unrestricted use, distribution, and reproduction in any medium, provided the original work is properly cited. 
Subgrade fill with red clay is often subjected to dry-wet cyclic process due to periodical variations in moisture content, leading to development of fissures within the soil matrix [7]. Fissures resulting from shrinkage can lead to reduction of the shear strength [8-11]. Therefore, lime [12], cement [13], sand [14], polymer [15] or fiber [16,17] have been used by many researchers to treat red clay to reduce its shrinkage. An optimum ratio of clay to sand was proposed after considering both the shrinkage and compressive strength results [18].

Both weathered phyllite and red clay are not suitable for the direct use as subgrade fill material due to their high moisture content, high liquid limit and high shrinkage. These two kinds of soils are often classified as unsuitable without any improvement. Therefore, lime or cement is often used to stabilize weathered phyllite, and some engineering properties of weathered phyllite have been enhanced [19-22]. However, production of lime and cement will not only require a lot of energy, but also cause substantial air pollution [23,24]. Furthermore, the cementation process usually needs a long time to be fulfilled [25], which is often not convenient for rapid subgrade construction using locally won soils. Recently a new blending method of the CWP soil with red clay at an optimal ratio has been proposed by Zhao et al. to effectively improve the shear strength of the subgrade [26].

In recent years, as more and more governmental authorities attach great importance to environmental protection, some high energy consuming industries producing reinforcement agents are restricted, which leads to a rapid rise in the price of reinforcement agents such as cement and lime [27-29]. Furthermore, with the increase of unsuitable soil disposal resulting from rapid development of infrastructures such as railway and highway construction, it is of vital importance to find a new way of re-using natural but poor-quality site won materials for subgrade fill during construction.

The traditional improvement method of enhancing unsuitable soils such as CWP soil and red clay entails using cement and lime as a reinforcement agent. This has attracted many researchers and has become widely accepted in the construction industry over the past few decades. In this paper, an improvement method based on deformation neutralization effects of CWP and red clay has been proposed so that the strength of the blended CWP soil with red clay can meet the minimum requirements of subgrade set out by the current code of practice. That is, the use of an appropriate amount of red clay will be able to stabilize the CWP soil by reducing its expansibility. Simultaneously, CWP will reduce the fissure rate of red clay, thus providing mutual enhancements of the basic characteristics of these two kinds of unsuitable soils. The research findings of this paper indicate that this new improvement method will enable the use of renewable materials for subgrade for railway and highways in large scale construction, hence reducing the use of cement and/or lime, resulting in savings in energy consumption and emission reduction.

\section{Laboratory Investigations}

\subsection{Experimental Material and Blending Ratio Design}

The completed weathered phyllite (CWP) soil and red clay in this study were obtained from south of Nanchang City, Jiangxi Province, China. The basic physical properties of CWP and red clay are shown in Tab. 1, and all tests were undertaken in accordance with the code for soil test of railway engineering (TB 10102-2010) [30].

The shear strength of CWP can be greatly and rapidly improved by adding red clay into CWP at various

blending ratios [26]. The experimental proportioning method was designed as follows: Based on the dry weight of CWP soil $\left(m_{0}\right)$ and a blending ratio $(\lambda)$, a portion of red clay at $0 \%, 20 \%, 40 \%, 60 \%, 80 \%$ and $100 \%$ was added into phyllite soil, respectively. The blending ratio, $\lambda=0 \%$ represents pure CWP and $100 \%$ pure red clay. The four blending ratios, $\lambda=20 \%, 40 \%, 60 \%$ and $80 \%$ respectively, represent the dry weight ratio of CWP soil to red clay being at 5:1, 5:2, 5:3 and 5:4, respectively. 
Table 1: The basic physical properties indexes of CWP and red clay

\begin{tabular}{|c|c|c|c|c|c|c|c|c|c|}
\hline \multirow{2}{*}{$\begin{array}{l}\text { Name } \\
\text { of soils }\end{array}$} & \multicolumn{3}{|c|}{ Particle size component content (\%) } & \multirow[t]{2}{*}{ Liquid limit (\%) } & \multirow[t]{2}{*}{ Plastic limit (\%) } & \multirow{2}{*}{$\begin{array}{l}\text { Plasticity } \\
\text { index }\end{array}$} & \multirow{2}{*}{$\begin{array}{l}\text { Natural moisture } \\
\text { content }(\%)\end{array}$} & \multirow[t]{2}{*}{ Relative density } & \multirow{2}{*}{$\begin{array}{l}\text { Natural density } \\
\left(\mathrm{g} . \mathrm{cm}^{-3}\right)\end{array}$} \\
\hline & $\begin{array}{l}\text { Sand group } \\
>0.075 \mathrm{~mm}\end{array}$ & $\begin{array}{l}\text { Silt group } \\
0.005-0.075 \mathrm{~mm}\end{array}$ & $\begin{array}{l}\text { Clay group } \\
<0.005 \mathrm{~mm}\end{array}$ & & & & & & \\
\hline CWP & 29 & 54.5 & 16.5 & 43.3 & 28.9 & 14.4 & 8.48 & 2.76 & 2.01 \\
\hline Red clay & 2 & 72.8 & 25.2 & 48.4 & 26.4 & 22.0 & 22.31 & 2.69 & 1.81 \\
\hline
\end{tabular}

In order to study the influence of initial moisture content $\left(w_{0}\right)$, compaction coefficient $(K)$, and blending ratio $(\lambda)$, on the performance of a blended soil, it was necessary to consider the design of these key parameters for sampling and laboratory testing. Considering the permitted variation of $w_{\mathrm{op}} \pm 2 \%$ by Chinese Railway Code-TB 10001-2016, the moisture contents of test samples were set as $16 \%, 18 \%$ and $20 \%$, respectively, and the compaction coefficients $(K)$ were selected to be at $89 \%, 91 \%$ and $93 \%$, respectively.

\subsection{Swell Tests}

The swell tests of the blended soils of CWP with red clay include free swell index test and free load swell index test.

Free swell index $\left(\delta_{e f}\right)$ is the ratio of the increased volume to the original volume of the soil sample when immersed in water without any constraint. The instrument used in this test is a $50 \mathrm{ml}$ measuring cylinder, and the volume after expansion is determined by observing the scale of the cylinder at the interface of soil and liquid after stabilization.

The free load swell index $\left(\delta_{e p}\right)$ is defined as the ratio of the deformation caused by the vertical expansion of the soil sample to the original height of the sample under the condition of no overlying load but with lateral restraint. The equipment used for $\delta_{e p}$ test was the WZ-2 type dilatometer manufactured by Nanjing Soil Instrument Factory, in which the diameter of sample was $61.8 \mathrm{~mm}$ and the height $20 \mathrm{~mm}$. After the sample was prepared, pure water was poured into the water tank of the WZ-2 dilatometer, with the water surface being maintained $5 \mathrm{~mm}$ above the top surface of the sample. During this soaking process, the dial gauge reading was taken once every $2 \mathrm{~h}$ until the difference between two readings is less than $0.01 \mathrm{~mm}$. The total expansion deformation, $\Delta h$, was recorded and then the free load swell index is calculated as the ratio of $\Delta h$ to the original height of the sample $(20.0 \mathrm{~mm})$.

\subsection{Dry-Wet Cycle Test}

Railway subgrade engineering generally requires compaction at the optimum moisture content $\left(w_{o p}\right)$, and the degree of compaction is not less than $91 \%$. As such test samples were prepared as follows: Initial moisture content $\left(w_{0}\right)$ is $18 \%$, compaction degree $(K)$ is $91 \%$, diameter is $152 \mathrm{~mm}$, and height is $100 \mathrm{~mm}$.

To simulate the maximum ground surface temperature of about $55^{\circ} \mathrm{C}$ in Nanchang in summer, the samples were continuously dried for $12 \mathrm{~h}$ in an oven at $55^{\circ} \mathrm{C}$. After $12 \mathrm{~h}$, the drying process was completed by measuring the weight of the sample every hour until its weight unchanged, and the moisture content reaches soaking moisture content $\left(w_{\text {sat }}\right)$. The wetting process was completed by placing the sample in a tank for $12 \mathrm{~h}$ soaking, which simulates continuous rainfall events in Nanchang City, Jiangxi Province, China. The drying and wetting process is a complete dry-wet cycle test. According to this method, each sample was tested for $1,2,3,4,5$ and 6 dry-wet cycles. The moisture content of drywet cycle path is shown in Fig. 1. 


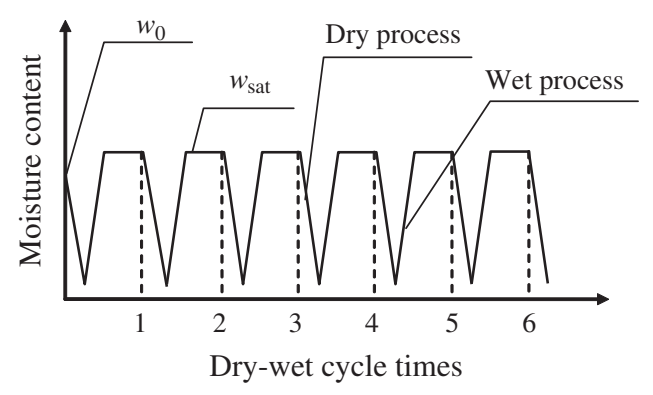

Figure 1: Dry-wet cycle path diagram

Based on the dry-wet cycle path of Fig. 1, the surface of the sample was photographed after each dry-wet cycle was completed. In doing so, the change pattern of fissure development can be obtained after each dry-wet cycle.

\section{Factors Affecting Swell Indexes}

\subsection{Blending Ratio Affecting on Swell Index}

The free swell index test results show that the free swell index of the CWP soil is $21.5 \%$, and that of red clay is $6.0 \%$. The variation of free swell index with blending ratio is shown in Fig. 2.

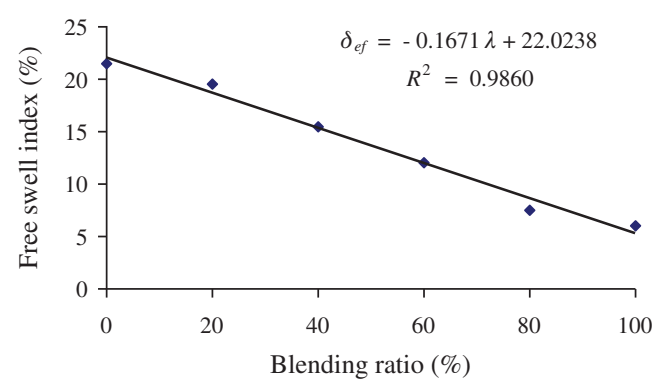

Figure 2: Variation of free swell index with blending ratio

The free swell index of the blended soil is lower than $40 \%$, which is the threshold of the expansive soil classification parameter. It can be seen from Fig. 2 that the blended soil is non-expansive soil and has the potential to be used as subgrade fill. As demonstrated in Fig. 2, the free swell index of the blended soil decreases approximately linearly with the increase of the blending ratio, with the correlation between $\delta_{e f}$ and $\lambda$ being shown in Eq. (1).

$\delta_{e f}=-0.1671 \lambda+22.0238$

When the blending ratio of red clay to CWP is $40 \%$, the free swell index is reduced by $27.9 \%$, which is very beneficial to control the swelling deformation of CWP soil.

\subsection{Analysis of Influencing Factors of Free Load Swell Index}

3.2.1 Effect of Soaking Time on the Free Load Swell Index

Taking blended soil samples with $w_{0}=18 \%$ and $K=89 \%$ as examples, the relationship between the free load swell index $\left(\delta_{e p}\right)$ and time (in hours) is shown in Fig. 3.

It can be seen from Fig. 3 that the blended soil swells rapidly after being soaked in water, and most of the expansion occurs within $0.5 \mathrm{~h}$. Taking the CWP soil as an example, $85.7 \%$ of the final swell was attained at 
$0.5 \mathrm{~h}, 91.0 \%$ at $1 \mathrm{~h}$, and the expansion was quasi-stable at $4 \mathrm{~h}$. It can be seen from the test results that the swell deformation can be completed in a relatively short period of time after soaking in water. Therefore, waterproof measures should be taken in the construction of subgrade in rainy season to avoid swelling and subsequent reduction or loss of shear strength.

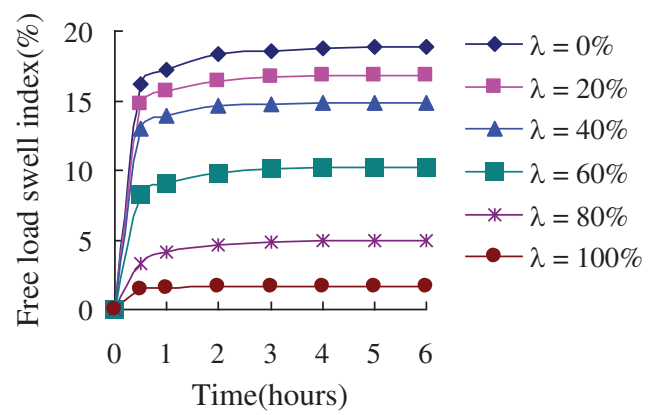

Figure 3: The relationship between $\delta_{e p}$ and time $\left(w_{0}=18 \%, K=91 \%\right)$

\subsubsection{The Influence of Blending Ratio on Free Load Swell Index}

In order to study the influence of blending ratio on $\delta_{e p}$, the relationship between $\delta_{e p}$ and $\lambda$ was studied experimentally when the moisture content $w_{0}=16 \%, 18 \%$ and $20 \%$, and the results are shown in Fig. 4 .

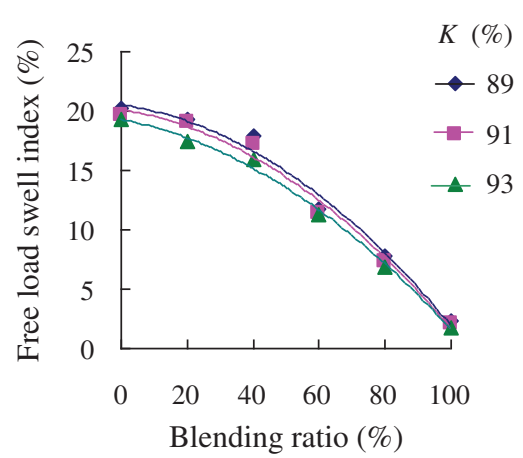

(a)

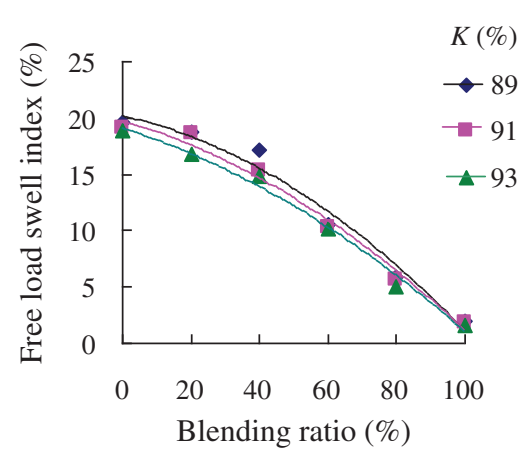

(b)

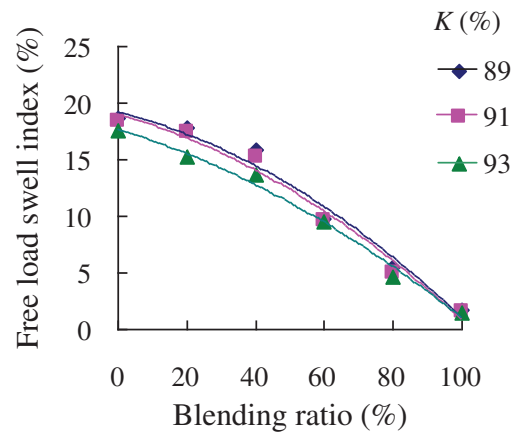

(c)

Figure 4: The variation law of $\delta_{e p}-\lambda$ (a) $w_{0}=16 \%$ (b) $w_{0}=18 \%$ (c) $w_{0}=20 \%$

As shown in Fig. 4, $\delta_{e p}$ decreases with the increase of $\lambda$. When $\lambda=0 \%, w_{0}=16 \%$, and $K=89 \%, \delta_{e p}$ reaches the maximum of $20.2 \%$; When $\lambda=100 \%, w_{0}=20 \%$ and $K=93 \%, \delta_{e p}$ is $1.5 \%$ and the smallest. Taking the sample with $w_{0}=18 \%$ and $K=91 \%$ as examples, the maximum $\delta_{e p}$ is about 10.6 times of the minimum value, so adding red clay into CWP soil can greatly reduce the swell performance of the CWP soil. Through data regression analysis, it can be concluded that the free load swell index decreases quadratically with the increase of red clay blending ratio, and the correlation can be expressed by Eq. (2).

$\delta_{e p}=a \lambda^{2}+b \lambda+c$

In Eq. (2): $a, b$ and $c$ are quadratic function fitting coefficients.

The fitted quadratic curve is shown in Fig. 4, and the fitting coefficients and correlation coefficients are ranging from 0.978 to 0.997 , as shown in Tab. 2 . 
Table 2: Fitting coefficients and correlation coefficient

\begin{tabular}{llllll}
\hline$w_{0}(\%)$ & $K$ & $a$ & $b$ & $c$ & $R^{2}$ \\
\hline 16 & 89 & -0.0015 & -0.0387 & 20.536 & 0.9869 \\
16 & 91 & -0.0014 & -0.0426 & 20.136 & 0.9887 \\
16 & 93 & -0.0012 & -0.0533 & 19.313 & 0.9966 \\
18 & 89 & -0.0012 & -0.0660 & 20.200 & 0.9782 \\
18 & 91 & -0.0010 & -0.0878 & 19.789 & 0.9867 \\
18 & 93 & -0.0009 & -0.0946 & 19.104 & 0.9908 \\
20 & 89 & -0.0011 & -0.0740 & 19.193 & 0.9808 \\
20 & 91 & -0.0010 & -0.0831 & 19.004 & 0.9812 \\
20 & 93 & -0.0007 & -0.0917 & 17.686 & 0.9909 \\
\hline
\end{tabular}

\subsubsection{Analysis of the Reasons for the Decrease of Free Load Swell Index}

According to the test results, the free load swell index of red clay is far less than that of CWP soil. After adding red clay into CWP soil, it is equivalent to adding a material with low swell index to the CWP soil. The mineral composition analysis was carried out by the type of D8 Advance X-RAY diffraction meter (XRD) produced by Bruker Company, Germany. In the test, the radiation source is $\mathrm{Cu}$ (wavelength is $154060 \mathrm{pm}$ ), and the scanning other parameters are 5.0/69.9998/0.0205 counting time $57.6 \mathrm{sec}, I(\max )=12104$, test temperature at $30^{\circ} \mathrm{C}$. The results of mineral composition analysis are shown in Tab. 3 .

Table 3: Test results of mineral composition analysis

\begin{tabular}{lllllll}
\hline Soil name & $\begin{array}{c}\text { Kaolinite } \\
(\%)\end{array}$ & Muscovite (\%) & Quartz (\%) & $\begin{array}{r}\text { Illite } \\
(\%)\end{array}$ & Chlorite (\%) & Montmorillonite (\%) \\
\hline CWP soil & 12.4 & 24.2 & 22.7 & 23 & 6.8 & 10.8 \\
Red clay & 4 & 29.3 & 32.3 & 22.4 & 11.9 & 0.0 \\
\hline
\end{tabular}

It can be seen from Tab. 3 that the CWP soil contains 10.8\% montmorillonite, so CWP soil has strong expansibility. Red clay does not contain montmorillonite, which is a strong expansive mineral. Therefore, adding red clay into the CWP soil is equivalent to diluting the content of montmorillonite. The content of montmorillonite decreases from $10.8 \%$ to $7.7 \%$, and the free load swell index decreases by $19.89 \%$ when the blending ratio is $40 \%$. Therefore, the decrease of expansive mineral content is one of the important factors for the low free load swell index of the blended soil.

\subsubsection{Effect of Initial Moisture Content (wo) on Free Load Swell Index}

The initial moisture content is the moisture content when soil samples compacted, and the variation relationships of free load swell index with moisture content are shown in Fig. 5.

As demonstrated in Fig. 5, $\delta_{e p}$ decreases approximately linearly with the increase of moisture content. Taking the sample with $K=91 \%$ and $\lambda=60 \%$ as an example, When the moisture content increases from $16 \%$ to $18 \%$ and from $18 \%$ to $20 \%$, the swell index decreases by $9.6 \%$ and $6.8 \%$, respectively. This is because the larger the initial moisture content is, the more water the soil particles absorb and have completed partial expansion, and the additional expansion is relatively smaller after sample saturation. Therefore, in engineering practice, the in-situ moisture content of the blended soil is usually set to be 
slightly higher than the optimum moisture content, which is beneficial to control the swell index of general fill after saturation.

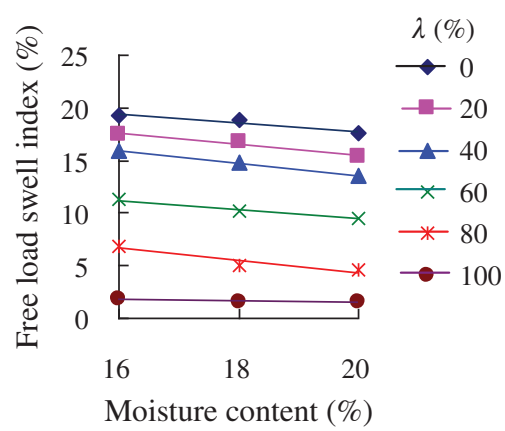

(a)

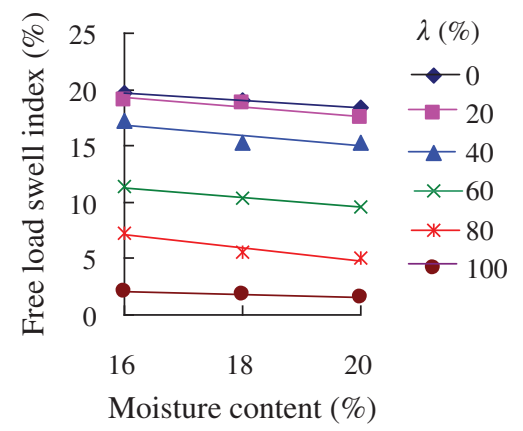

(b)

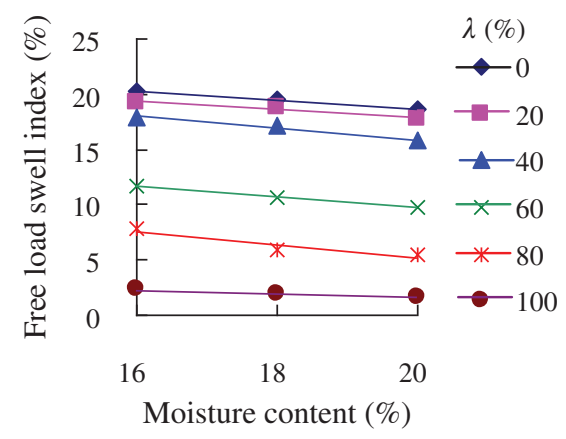

(c)

Figure 5: The variation law of $\delta_{e p^{-}} w_{0}$ (a) $K=89 \%$ (b) $K=91 \%$ (c) $K=93 \%$

\subsubsection{Influence of Compaction Coefficient $K$ on $\delta_{e p}$}

The variation relationships of free load swell index with compaction coefficient are shown in Fig. 6.

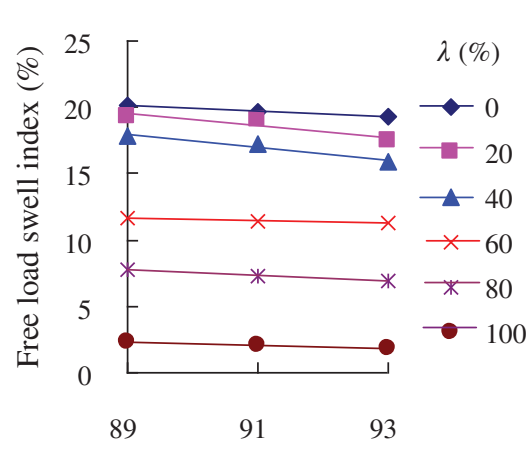

Compaction coefficient $(\%)$

(a)

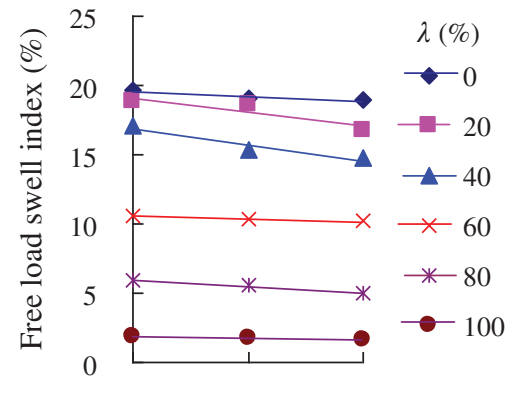

$89 \quad 91 \quad 93$

Compaction coefficient $(\%)$

(b)

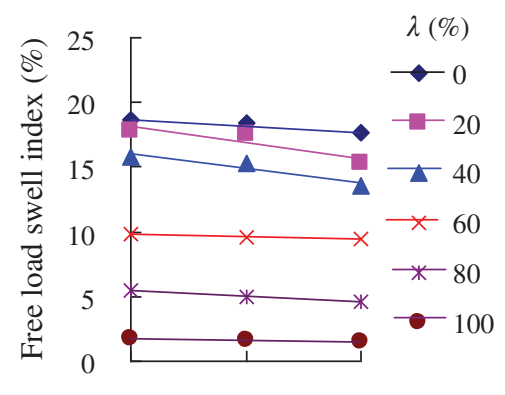

$89 \quad 91 \quad 93$

Compaction coefficient $(\%)$

(c)

Figure 6: The variation law of $\delta_{e p}-K(\mathrm{a}) w_{0}=16 \%$ (b) $w_{0}=18 \%$ (c) $w_{0}=20 \%$

As demonstrated in Fig. 6, $\delta_{e p}$ decreases approximately linearly with the increase of compaction coefficient. The larger the compaction coefficient of fine-grained soil, the higher the cohesive force [26] of soil matrix is, requiring a greater force to overcome the expansion.

\subsubsection{Analysis of the Influence of $w_{0}, K$ and $\lambda$ on $\delta_{e p}$}

From the previous analysis, the free load swell index $\delta_{e p}$ has a quadratic function relationship with $\lambda$, and has a linear relationship with $w_{0}$ and $K$. The relationship among $\delta_{e p}$ and $w_{0}, K$ and $\lambda$ can be obtained by using Excel's regression method. The 95\% confidence level is adopted, and the results are shown in Eq. (3).

$\delta_{e p}=-0.417 w_{0}-0.281 K-0.0011 \lambda^{2}-0.070 \lambda+52.471$

When Eq. (3) is used to predict the free load swell index of each blended soil, the average relative error is $11.7 \%$. When the blending ratio is less than or equal to $80 \%$, the prediction accuracy is better. When the blending ratio is $100 \%$, the maximum relative error reaches $108 \%$, noting the relative error between the predicted value and the measured value is very large. This is because the maximum free load swell index 
of the red clay itself is only $1.8 \%$. When the absolute error is small, it may cause a large relative error. As the purpose of this research is to investigate the engineering properties of blended soils rather than the expansion of pure red clay, nine sets of data have been considered for regression analysis, with $100 \%$ blending ratio of red clay being discarded. Regression analysis of the data shows that the analysis and prediction model can be expressed by Eq. (4).

$\delta_{e p}=-0.477 w_{0}-0.320 K-0.0018 \lambda^{2}-0.023 \lambda+54.810$

The absolute and relative errors of $\delta_{e p}$ are shown in Fig. 7. In Fig. 7, $N$ is test number.

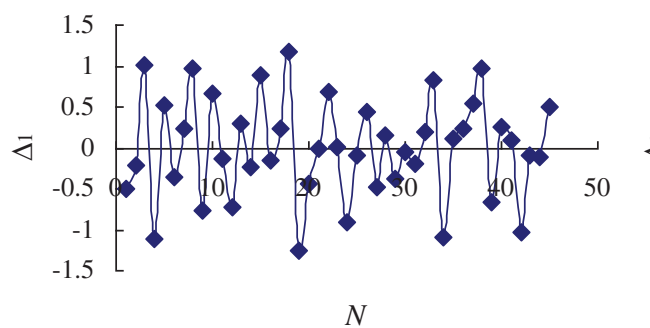

(a)

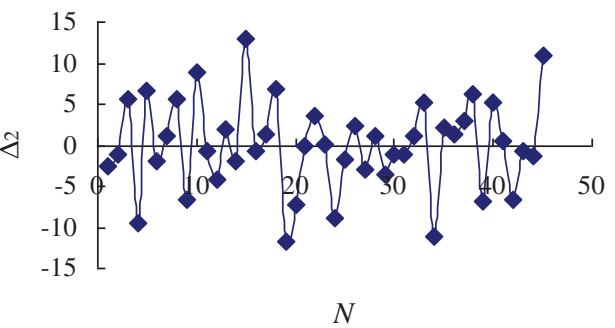

(b)

Figure 7: $\delta_{e p}$ absolute error and relative error (excluded red clay) (a) $\delta_{e p}$ absolute error (b) $\delta_{e p}$ relative error

The maximum absolute error between the estimated value and the measured value calculated by Eq. (4) is $1.25 \%$, with the maximum relative error of $12.96 \%$, the average relative error of $4.18 \%$, and the correlation coefficient of 0.985 . From the point of view of fitting error, it is feasible to use Eq. (4) to predict the amount of free load swell index of blended soils with different blending ratios.

\subsection{Influencing Factors of Fissure Development of Blended Soil}

Red clay is a kind of typical soil with fissures caused by moisture change and shrinkage. When water penetrates the subgrade through the fissures, the strength of subgrade will be greatly reduced.

The fissure density is often used to evaluate the evolution of the micro-structure within the red clay after the dry-wet cycle [31,32]. The fissure density is often defined as the ratio of the total area of fissures on the surface to the cross-sectional area of the test sample. Thus it is often calculated by Eq. (5) below:

$\delta_{f A}=\frac{\sum_{i=1}^{n} A_{i}}{A} \times 100 \%$

where $\delta_{f A}$ is the fissure density, $A$ is the cross-sectional area of sample, $A_{i}$ is the area occupied by the $i^{\text {th }}$ fissure, and the $n$ is the total number of fissures observed.

Fissure density calculation method can be realized by programming. Firstly, the color image is converted into black and white two-color image by algorithm, and the fissure density is calculated by the proportion of black and white pixels. For specific calculation method, refer to reference [33].

Fissure length index is another important parameter reflecting the degree of fissure development. The longer the fissure length per unit area, the higher the degree of fissure development is. Fissure length index can be defined as the total length of fissure per unit area, which can be expressed by Eq. (6). 
$\delta_{f L}=\frac{\sum_{i=1}^{n} L_{i}}{A} \times 100 \%$

where $\delta_{f L}$ is the fissure length index, $L_{i}$ is the length of the $i$-th fissure, $A$ is the cross-sectional area of sample and $n$ is the total number of fissures observed.

During dry-wet cycles, some blended soil samples produced irregular fissures on the surface, and it is difficult to count the length of fissures by traditional methods. It can be measured by AutoCAD multisegment line tracking method, and then the actual length of cracks can be obtained by unit conversion [33].

The factors that affect the fissure development include diameter of the sample, blending ratio, moisture content, compaction coefficient, dry-wet cycles and so on, which are discussed in the following sections.

\subsubsection{Effect of Sample Diameter on Fissure Development}

In all blended soils, red clay has the largest number of fissures developed, so red clay samples were used to illustrate the influence of sample diameter on the fissure development. The diameters of samples prepared in laboratory are $61.8 \mathrm{~mm}, 100.0 \mathrm{~mm}$, and $152.0 \mathrm{~mm}$, respectively, and the shrinkage fissures developed with different sample diameters are shown in Figs. 8a-8c.

(a)

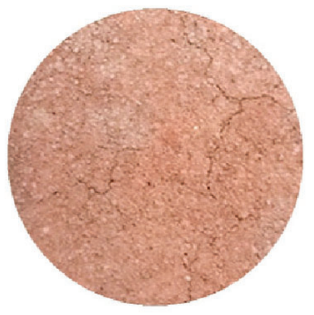

(c)

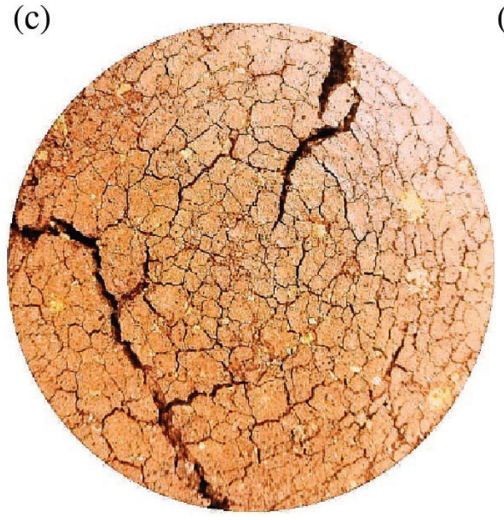

(b)

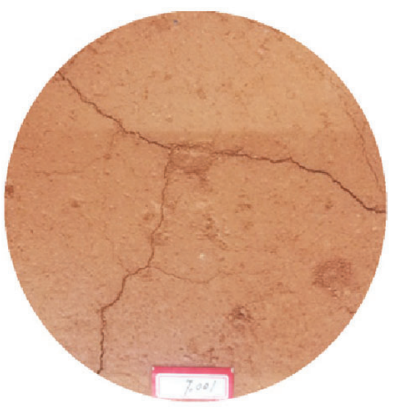

(d)

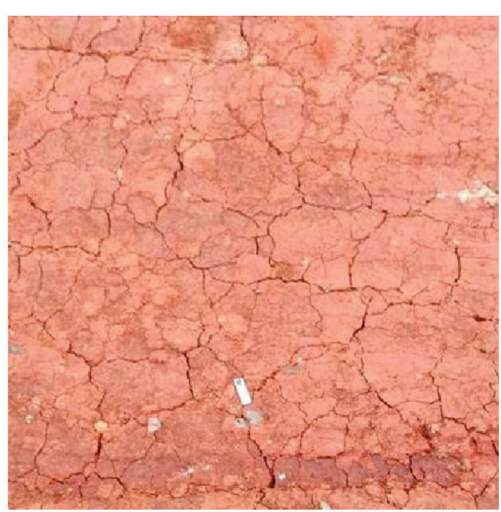

Figure 8: Comparison of fissure development between test sample and subgrade (a) $d=61.8 \mathrm{~mm}$ (b) $d=100 \mathrm{~mm}(\mathrm{c}) d=152 \mathrm{~mm}(\mathrm{~d})$ Fissures development in subgrade

By comparing the fissure development between the samples in laboratory and subgrade in field (see Fig. 8d), the sample with greater diameter was found to better simulate the actual subgrade situation. Therefore, the statistical analysis was based on samples with a diameter of $152 \mathrm{~mm}$ in this research. 


\subsubsection{Effect of Dry-Wet Cycles on Fissure Density}

The fissure density of blended soil samples increases with the increase of dry-wet cycles, but after five drying and wetting cycles, as shown in Fig. 9, the fissure density tends to reach an asymptote without any appreciable increase by the $6^{\text {th }}$ cycle.

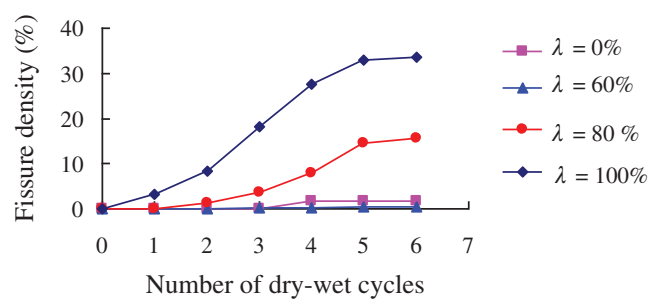

Figure 9: Variation of fissure density with dry-wet cycles

\subsubsection{Characteristics of Fissure Development in Blended Soil}

According to the results of dry-wet cycle test, the fissure development of laboratory test soil sample nearly stopped after five dry-wet cycles, and the sixth test was taken as the result of blended soil fissures. After six dry-wet cycles, the fissure development status of the blended soil samples with different blending ratios is shown in Fig. 10.
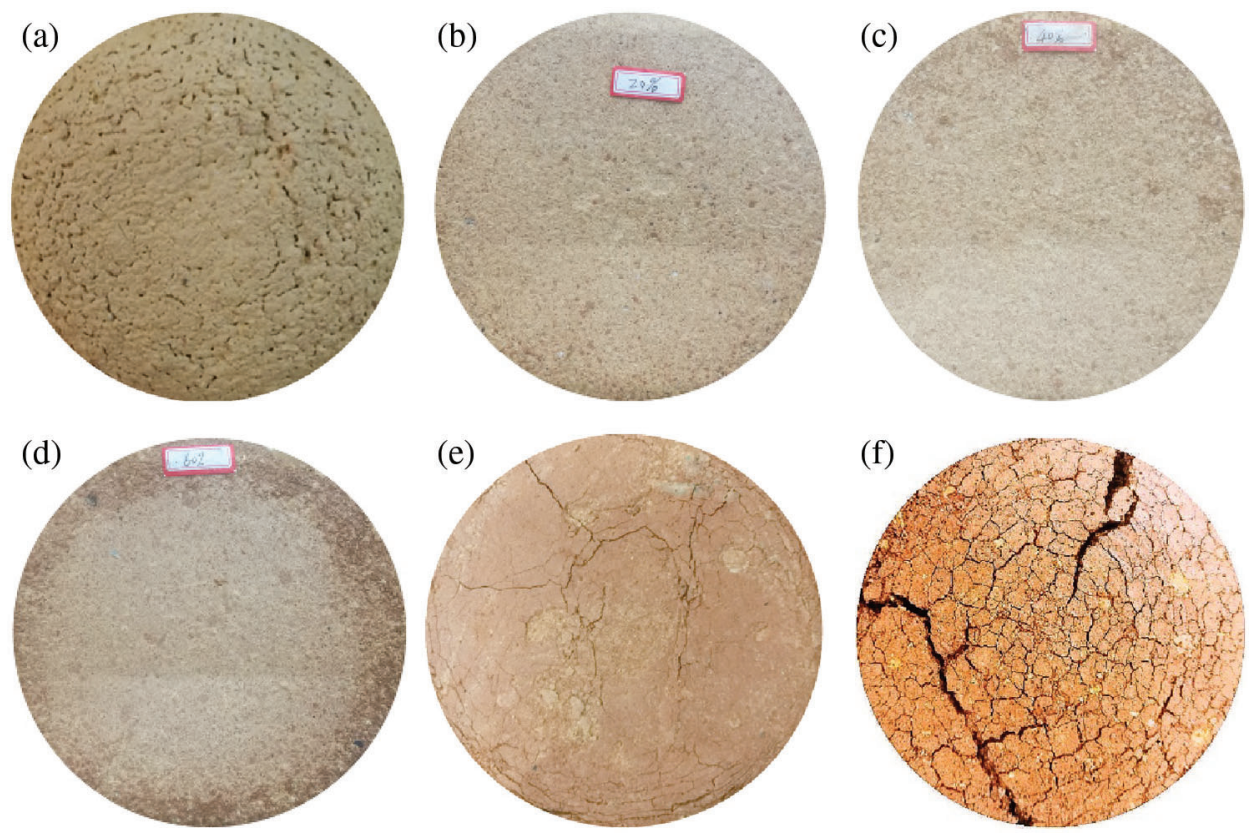

Figure 10: Final fissure diagram of the sample at different blend ratios (a) $\lambda=0 \%$ (b) $\lambda=20 \%$ (c) $\lambda=40 \%$ (d) $\lambda=60 \%$ (e) $\lambda=80 \%$ (f) $\lambda=100 \%$

As can be seen from Fig. 10, the fissure development can be divided into the following three Types. Type I)-Many isolated pores induced by expansion: When the blending ratio is $0 \%$ (pure CWP soil), due to the relatively large swell index of the CWP soil, there are some bulging holes on the surface of the sample. After six drying and wetting cycles, the bulging holes remain on the surface of the sample, forming some discontinuous holes, as shown in Fig. 10a. Type II)-No detectable fissure type: When the 
blending ratio was $20 \%, 40 \%, 60 \%$, there was no detectable fissures after six times dry-wet cycles (see Figs. $10 \mathrm{~b}-10 \mathrm{~d}$. Type III)-Extensive fissure type: When the blending ratio is at $80 \%$ and $100 \%$, there are large number of fissures developed on the surface of the sample after six dry-wet cycles. A mesh-like network of fissures is evident on the surface, and two larger fissures with a width of more than $7 \mathrm{~mm}$ observed at a blending ratio of $100 \%$, as shown in Figs. $10 \mathrm{e}$ and $10 \mathrm{f}$.

\subsubsection{Influence of Blending Ratio on Fissure Density}

By analyzing the fissure density of the blended soil with 6 different blending ratios after 6 dry-wet cycles, the relationship between the fissure density and the the blending ratio can be obtained for the blended soils, as shown in Fig. 11.

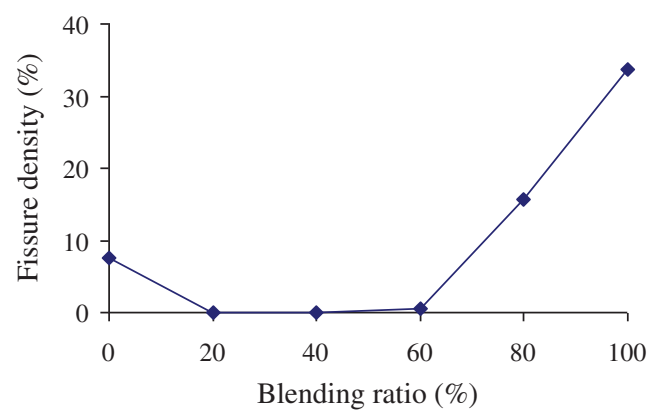

Figure 11: Variation of fissure density with blending ratios in blended soils

During dry-wet cycles, a large number of bulging holes remain on the surface of the CWP soil samples (Fig. 10a), which can also be regarded as a channel for water immersion into subgrade, and thus can be regarded as a form of fissure. As shown in Fig. 11, the fissure density of red clay can reach $33.64 \%$ and that of the CWP soil can reach 7.51\%, and the fissure density decreases first and then increases with the increase of blending ratio. When the blending ratio are $20 \%$ and $40 \%$, there is no visible fissures on the surface of the samples, so the fissure density is virtually zero. When the blending ratio of red clay in the blended soil is reduced from $100 \%$ to $80 \%$ and $60 \%$, the fissure density decreases to $15.63 \%$ and $0.476 \%$, respectively, which is $53.54 \%$ and $98.59 \%$ lower than that of red clay. Therefore, it can be inferred that after adding red clay into the CWP soil, the fissure density is significantly reduced, and the swell deformation of the CWP soil can also be reduced at the same time.

\subsubsection{Effect of Blending Ratio of Red Clay on Fissure Length Index}

The variation of fissure length index with blending ratio is shown in Fig. 12.

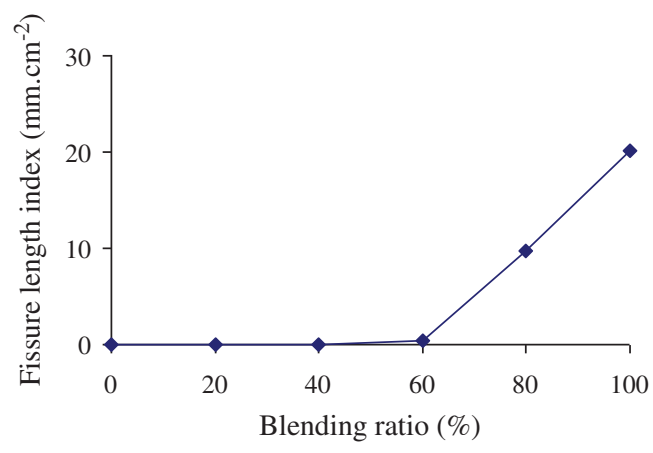

Figure 12: Variation law of fissure length index with blending ratios 
It can be seen from Fig. 10a that the CWP soil is a discontinuous hole due to expansion, and the hole has discontinuity, so the fissure length index is not counted. As shown in Fig. 12, the fissure length index of pure red clay is $20.15 \mathrm{~mm} / \mathrm{cm}^{2}$. When the bending ratio of red clay is reduced from $100 \%$ to $80 \%$ and $60 \%$, the fissure length index is reduced to $9.50 \mathrm{~mm} / \mathrm{cm}^{2}$ and $0.43 \mathrm{~mm} / \mathrm{cm}^{2}$, respectively, which are $51.60 \%$ and $97.88 \%$ lower than that of pure red clay. When the bending ratio is reduced to $40 \%$ and $20 \%$, the fissure length index decreases to zero. Therefore, in view of the fissure development against the blending ratios, the best blending ratio is $20 \%$ and $40 \%$, and the reduction in fissure length index of the blended soil is also very significant with a blending ratio $60 \%$.

\section{Discussion of Neutralization Effects}

\subsection{Effects on Decrease of Swell Property of CWP Soil}

The chemical reactions in ion exchange follow the law of mass action, but the reactions are restricted by the number of exchange sites on the mineral and by the strength of the bonding of the exchangeable cations to the mineral surface [34], Ordinary high valence cations can exchange low valence cations of soil and make the diffusion layer thinner [35-37]. The test results of element content analysis of the CWP soil and red clay are shown in Tab. 4, and the analysis shows that the iron content in red clay is much higher than that in the CWP soil. When the CWP soil is blended with red clay, a certain amount of iron ions $\left(\mathrm{Fe}^{3+}\right)$ can be precipitated from the red clay under certain conditions, which can exchange with the CWP soil. $\mathrm{Fe}^{3+}$ replaces $\mathrm{K}^{+}$in montmorillonite and illite, making the diffusion layer of expansive mineral particles in the CWP soil thinner, greatly reducing the free swell index of the CWP soil and reducing the liquid limit of CWP soil. In addition, according to the above, the free swell index of red clay is far less than that of the CWP soil. Adding red clay into CWP soil is equivalent to diluting the content of expansive minerals, which is also an important reason for reducing the free swell index.

Table 4: Quantitative analysis of elements content

\begin{tabular}{|c|c|c|c|c|c|c|c|}
\hline \multicolumn{4}{|c|}{ Red clay } & \multicolumn{4}{|c|}{ CWP soil } \\
\hline Elements & Mass percent (\%) & Oxide & Oxide percentage (\%) & Elements & Mass percent (\%) & Oxide & Oxide percentage (\%) \\
\hline $\mathrm{O}$ & 31.98 & - & & $\mathrm{O}$ & 54.89 & - & \\
\hline $\mathrm{Al}$ & 18.88 & $\mathrm{Al}_{2} \mathrm{O}_{3}$ & 17.05 & $\mathrm{Mg}$ & 0.33 & $\mathrm{MgO}$ & 0.62 \\
\hline $\mathrm{Si}$ & 27.18 & $\mathrm{SiO}_{2}$ & 23.57 & $\mathrm{Al}$ & 12.49 & $\mathrm{Al}_{2} \mathrm{O}_{3}$ & 27.48 \\
\hline K & 5.9 & $\mathrm{~K}_{2} \mathrm{O}$ & 3.68 & $\mathrm{Si}$ & 23.83 & $\mathrm{SiO}_{2}$ & 59.25 \\
\hline \multirow[t]{2}{*}{$\mathrm{Fe}$} & 16.06 & $\mathrm{Fe}_{2} \mathrm{O}_{3}$ & 7.0 & K & 2.42 & $\mathrm{~K}_{2} \mathrm{O}$ & 2.56 \\
\hline & & & & $\mathrm{Fe}$ & 6.04 & $\mathrm{Fe}_{2} \mathrm{O}_{3}$ & 10.09 \\
\hline
\end{tabular}

\subsection{Effects on Decrease of Fissure Development in Red Clay}

According to the dry-wet cycle test results, the fissure density of blended soil samples is far less than that of red clay. Further there is no visible fissure developed in the soil samples when the blending ratio of red clay is between $20 \%$ and $40 \%$. The CWP soil has strong expansibility after soaking, and it still retains the original swell deformation after dry-wet cycles (see Fig. 10a). On the contrary, red clay has strong shrinkage, resulting in a lot of developed fissures resided in the soil matrix after dry-wet cycles. After blending the CWP soil with red clay, expansion of the CWP soil and shrinkage deformation of red clay produces neutralization effects, resulting in far lower rates of fissure development in the blended soil than that of pure red clay. 
The other reason for the decrease of fissure development is that the particle size of the CWP soil is larger than that of red clay, resulting in contraction and tension isolation effect. The characteristics of the particles were measured by the JSM 6701F type field emission scanning electron microscope with energy spectrometer produced by Japan Electronics Company. Fig. 13 shows the SEM images of CWP soil particles and red clay particles in the blended soil $(\lambda=80 \%)$ with magnification of 2,000 times and 10,000 times, respectively. According to the analysis results in the Fig. 13, the grain size of the CWP soil is ranging from $10 \mu \mathrm{m}$ to $45 \mu \mathrm{m}$, and that of red clay $1 \mu \mathrm{m}$ to $4 \mu \mathrm{m}$. According to the previous research, adding sand into red clay can significantly reduce the fissure density of red clay [14]. In the blended soil, it is equivalent to adding coarser CWP soil particles into the red clay, and the proportion of the CWP soil particles in the blended soil is prevalent, thus the connection interfaces among most of the red clay particles has been cut off by CWP particles. The shrinkage stresses caused by the contraction of red clay particles are also reduced accordingly, resulting in less fissure development comparing with that of pure clay.

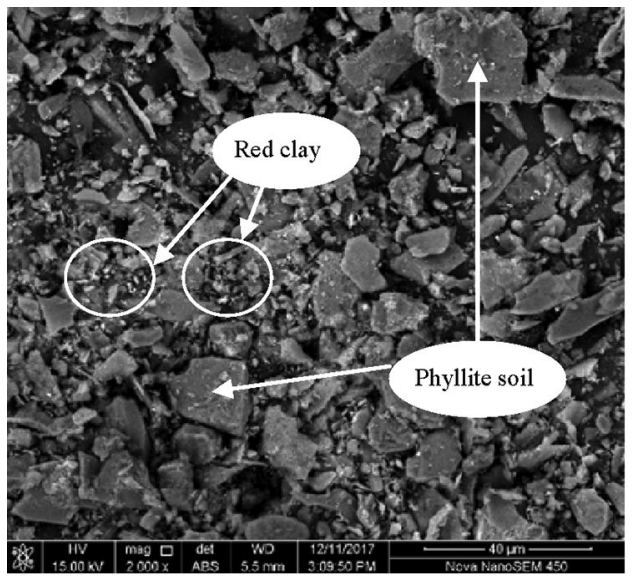

(a)

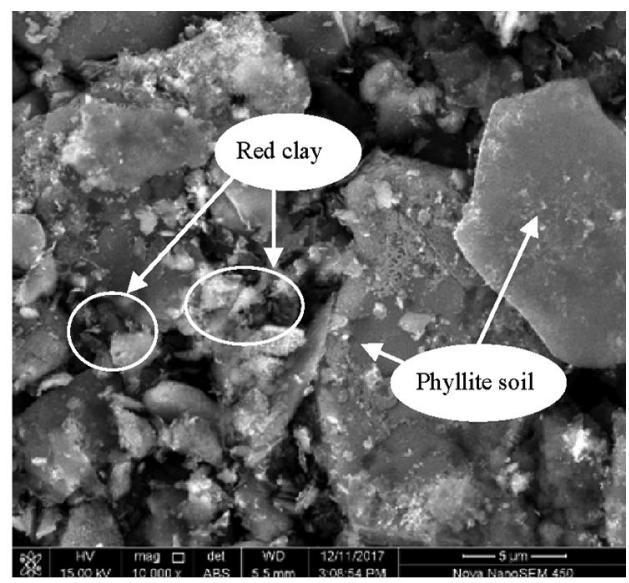

(b)

Figure 13: Comparison of micro particle size of blended soil $(\lambda=80 \%)$ (a) $2000 x$ (b) $10000 x$

\subsection{Determination of Optimum Blending Ratio}

The high liquid limit clay has poor water stability, easy to expand and soften when meeting water, therefore, the liquid limit value is an important standard for filler selection in China Railway Code (TB 10001-2016) [38]. The liquid plastic limit test results of mixed soil are shown in Tab. 5.

Table 5: Test results of liquid plastic limit of mixed soil

\begin{tabular}{llll}
\hline Blending ratio (\%) & Plastic limit (\%) & Liquid limit (\%) & Plasticity index \\
\hline 0 (pure CWP) & 28.9 & 43.3 & 14.4 \\
20 & 24.4 & 39.6 & 15.3 \\
40 & 23.1 & 37.1 & 14.0 \\
60 & 25.0 & 42.6 & 17.6 \\
80 & 24.8 & 44.3 & 19.4 \\
100 (pure red clay) & 26.4 & 48.4 & 22.0 \\
\hline
\end{tabular}


Considering that the requirement of liquid limit is less than $40 \%$ in the code TB 10001-2016, the blending ratio of red clay should be in a controlled range from $13 \%$ to $52 \%$ [26]. The free load swell index decreases with the increase of the blending ratio, and the bearing capacity of the compacted subgrade increases with the increase of the blending ratio when the blending ratio is in the range of $13 \%-$ $52 \%$. The fissure density of blended soil can be ignored when the blending ratio is in the range of $20 \%-$ $60 \%$. Therefore, the optimum blending ratio can be considered as $52 \%$, and the applied optimum blending ratio can be taken as $50 \%$ for ease of engineering applications. Under the conditions of the moisture content of subgrade compaction is $18 \%$; the compaction coefficient is $91 \%$; and the blending ratio is $50 \%$, it can be obtained from the analysis of the test results that the free load swell index is $10.5 \%$; fissure density is $0.238 \%$ and the fissure length index is $38.8 \mathrm{~mm} / \mathrm{cm}^{2}$. According to the data in this research, the free load swell index of the CWP soil is reduced by about $45 \%$ and the fissure density is reduced by $99.3 \%$ compared with that of red clay. Therefore, the free load swell index and shrinkage can be effectively suppressed by considering the blending ratio of $50 \%$.

In summary, the neutralization effects of expansion deformation of the CWP soil and shrinkage deformation of red clay can not only reduce the expansion, but also the fissure development of a blended soil. This improves the overall performance of the blended soil when immersed in water. Furthermore, the liquid limit of the blended soil has been found to be less than $40 \%$, meaning it is now classified as group $\mathrm{C}$ fill as per railway code. Use of the blended soil will thus reduce the disposal volume of unsuitable materials of both CWP and red clay with liquid limits of more than $40 \%$. The in-situ trial test results also show that the shear strength and bearing capacity of the CWP soil can be greatly improved by adding red clay into CWP [26]. This blending method can achieve a higher bearing capacity immediately after rolling compaction is completed, which is fundamentally different from the traditional lime and cement stabilization methods which need a certain curing time to achieve the higher strength.

\section{Conclusions}

Through this experimental research, the following conclusions can be drawn:

(1) The free load swell index $\left(\delta_{e p}\right)$ of the blended soil decreases with the increase of the blending ratio in a quadratic function and decreases almost linearly with the increase of the compaction coefficient and the moisture content. If the blending ratio of $100 \%$ (pure red clay) is removed, a generalized mathematical model can be established for variation of $\delta_{e p}$ with $\lambda, K$, and $w_{0}$. It is found that an increase in blending ratio, compaction coefficient, and moisture content is beneficial to control $\delta_{e p}$ of the blended soil.

(2) Red clay easily develops fissures under the action of dry-wet cycles, and the fissure density can reach $33.4 \%$ for the tested samples. The fissure density is greatly reduced when the CWP soils are blended with red clay. The fissure density is reduced by $100 \%$ relative to the red clay when the blending ratio ranges between $20 \%$ and $40 \%$, and the fissure density of the blended soil is relatively reduced by $97.88 \%$ when the blending ratio is $60 \%$.

(3) Through the blending of the CWP soil with red clay, the swell and shrinkage deformations have been neutralized to a certain extent. That is, the swell index of the CWP soil is reduced, and the fissure development of the red clay is also greatly reduced simultaneously. Based on the liquid limit of the blended soil required in the Chinese railway code, the optimum blending ratio of $50 \%$ has been proposed for practical applications. Under the condition of $\lambda=50 \%, \delta_{e p}$ of the blended soil is reduced by $45 \%$ relative to the CWP soil, and the fissure density is reduced by $99.3 \%$ relative to the pure red clay.

(4) This research has shown that it is feasible to use the neutralization effect of expansion and contraction of two unsuitable soils to suppress the free load swell index of the CWP soil and fissure development density of red clay. The results also show that the shear strength of the blended soil at the proposed optimum blending ratio of $50 \%$ for roadbed can meet the requirements of the subgrade standard. As such, the improvement method by means of neutralizing the CWP soil and red clay will not only greatly reduce the amount of 
disposal of two unsuitable soils but also the amount of lime and/or cement used in the conventional stabilization method. This will reduce costs while significantly increasing environmental benefits.

Funding Statement: This work is supported by the National Natural Science Foundation of China (Grant Nos. 52068027, 51668018, 51768021).

Conflicts of Interest: The authors declare that they have no conflicts of interest to report regarding the present study.

\section{References}

1. Liu, F. F., Mao, X. S., Zhang, H., Liu, L., Wu, Q. (2020). Investigating the deformation property of weathered phyllite filling subgrade. Journal of Testing and Evaluation, 48(5), 20170743. DOI 10.1520/JTE20170743.

2. Feng, W., Huang, R., Li, T. (2012). Deformation analysis of a soft-hard rock contact zone surrounding a tunnel. Tunnelling and Underground Space Technology, 32(4), 190-197. DOI 10.1016/j.tust.2012.06.011.

3. Phartiyal, B., Sharma, A. (2009). Soft-sediment deformation structures in the late quaternary sediments of ladakh: Evidence for multiple phases of seismic tremors in the north western himalayan region. Journal of Asian Earth Sciences, 34(6), 761-770. DOI 10.1016/j.jseaes.2008.11.008.

4. Li, X. Z., Wang, G. F., Cao, L. (2014). Test research on influence of water and mineral composition on physical and mechanical properties of phyllite. Applied Mechanics and Materials, 496, 2398-2401. DOI 10.4028/www. scientific.net/AMM.496-500.2398.

5. Hu, K., Feng, Q., Wang, X. (2017). Experimental research on mechanical property of phyllite tunnel surrounding rock under different moisture state. Geotechnical and Geological Engineering, 35(1), 303-311. DOI 10.1007/ s10706-016-0107-6.

6. Garzón, E., Sánchez, P. J., Romero, E. (2010). Physical and geotechnical properties of clay phyllites. Applied Clay Science, 48(3), 307-318. DOI 10.1016/j.clay.2009.12.022.

7. Du, B., Bai, H. B., Wu, G. M. (2019). Dynamic compression properties and deterioration of red-sandstone subject to cyclic wet-dry treatment. Journal of Advances in Civil Engineering, 2(1), 1-9. DOI 10.30659/jacee.2.1.01-14.

8. Zhao, Y. L., Gao, Y., Zhang, Y. L., Jia, Y. S. (2018). Effect of fines on the drying crack resistance of composite soil stabilizer-stabilized gravel soil. Road Materials and Pavement Design, 20(6), 1255-1274. DOI 10.1080/ 14680629.2018.1439766.

9. Subhradeep, D., Monowar, H. (2018). The strength behaviour of lime-stabilized plastic fibre-reinforced clayey soil. Road Materials and Pavement Design, 20(8), 1757-1778. DOI 10.1080/14680629.2018.1468803.

10. Tirupan, M., Tuncer, B. E., James, M. T. (2017). Study on flexural strength, modulus, and fatigue cracking of cementitiously stabilized materials. Road Materials and Pavement Design, 19(7), 1546-1562. DOI 10.1080/ 14680629.2017.1325772.

11. Xu, Y. W., David, J. W., Mehdi, S. (2020). Investigation of shear strength of interface between roadbase and geosynthetics using large-scale single-stage and multi-stage direct shear test. Road Materials and Pavement Design, 21(6), 1588-1611. DOI 10.1080/14680629.2018.1561378.

12. Stoltz, G., Cuisinier, O., Masrouri, F. (2012). Multi-scale analysis of the swelling and shrinkage of a lime-treated expansive clayey soil. Applied Clay Science, 61(4), 44-51. DOI 10.1016/j.clay.2012.04.001.

13. Sabir, B. B., Wild, S., Bai, J. (2001). Metakaolin and calcined clays as pozzolans for concrete: A review. Cement and Concrete Composites, 23(6), 441-454. DOI 10.1016/S0958-9465(00)00092-5.

14. Omidi, G. H., Prasad, T. V., Thomas, J. C., Brown, K. W. (1996). The influence of amendments on the volumetric shrinkage and integrity of compacted clay soils used in landfill liners. Water, Air, and Soil Pollution, 86(1-4), 263274. DOI 10.1007/BF00279161.

15. Azzam, W. R. (2014). Utilization of polymer stabilization for improvement of clay microstructures. Applied Clay Science, 93(3), 94-101. DOI 10.1016/j.clay.2014.03.006.

16. Fatahi, B., Le, T. M., Fatahi, B., Khabbaz, H. (2013). Shrinkage properties of soft clay treated with cement and geofibers. Geotechnical and Geological Engineering, 31(5), 1421-1435. DOI 10.1007/s10706-013-9666-y. 
17. Zhang, D. B., Zhang, Y., Cheng, T. (2018). Measurement of grass root reinforcement for copper slag mixed soil using improved shear test apparatus and calculating formulas. Measurement, 118(1), 14-22. DOI 10.1016/j. measurement.2018.01.005.

18. Emiroğlu, M., Yalama, A., Erdoğdu, Y. (2015). Performance of ready-mixed clay plasters produced with different clay/sand ratios. Applied Clay Science, 115, 221-229. DOI 10.1016/j.clay.2015.08.005.

19. Garzón, E., Cano, M., O’Kelly, B. C., O’Kelly, B. C., Sanchez, P. J. (2015). Phyllite clay-cement composites having improved engineering properties and material applications. Applied Clay Science, 114(9), 229-233. DOI 10.1016/j.clay.2015.06.006.

20. Garzón, E., Cano, M., O'Kelly, B. C., Sanchez, P. J. (2016). Effect of lime on stabilization of phyllite clays. Applied Clay Science, 123(9), 329-334. DOI 10.1016/j.clay.2016.01.042.

21. de Oliveira, T. F., Beck, M. H., Escosteguy, P. V., Bortoluzzi, E. C., Modolo, M. L. (2015). The effect of the substitution of hydrated lime with phyllite on mortar quality. Applied Clay Science, 105(1), 113-117. DOI 10.1016/j.clay.2014.12.028.

22. Garzón, E., Sánchez-Soto, P. J. (2015). An improved method for determining the external specific surface area and the plasticity index of clayey samples based on a simplified method for non-swelling fine-grained soils. Applied Clay Science, 115, 97-107. DOI 10.1016/j.clay.2015.07.015.

23. Zhang, S., Worrell, E., Crijnsgraus, W. (2015). Evaluating co-benefits of energy efficiency and air pollution abatement in China's cement industry. Applied Energy, 147, 192-213. DOI 10.1016/j.apenergy.2015.02.081.

24. Michael, E. B., Stefanie, H. (2010). Identifying improvement potentials in cement production with life cycle assessment. Environmental Science \& Technology, 44(23), 9143-9149. DOI 10.1021/es100771k.

25. Yao, K., Chen, Q. S., Xiao, H. W., Liu, Y. (2020). Small-strain shear modulus of cement-treated marine clay. Journal of Materials in Civil Engineering, 32(6), 04020114. DOI 10.1061/(ASCE)MT.1943-5533.0003153.

26. Zhao, X. S., Fu, Z. T., Yang, Q. J., Yao, K., Geng, D. X. et al. (2020). Subgrade fill strength and bearing characteristics of weathered phyllite blended with red clay. Road Materials and Pavement Design, 3(4), 1-20. DOI 10.1080/14680629.2020.1773906.

27. Gu, Z. H., Fang, A. G., Hua, S. D., Zhao, Q. Z., Sun, L. D. et al. (2021). Development of a soil stabilizer for road subgrade based on original phosphogypsum. Journal of Renewable Materials, 9(2), 253-268. DOI 10.32604/ jrm.2021.011912.

28. Li, W., Gao, S. (2018). Prospective on energy related carbon emissions peak integrating optimized intelligent algorithm with dry process technique application for China's cement industry. Energy, 165(1), 33-54. DOI 10.1016/j.energy.2018.09.152.

29. Shan, Y., Liu, Z., Guan, D. (2016). $\mathrm{CO}_{2}$ emissions from China's lime industry. Applied Energy, 166, 245-252. DOI 10.1016/j.apenergy.2015.04.091.

30. Ministry of Railways of the People's Republic of China (2010). Code for soil test of railway engineering (TB 10102-2010). China Railway Publishing House, Beijing, China.

31. Li, J. H., Zhang, L. M., Wang, Y., Fredlund, D. G. (2009). Permeability tensor and representative elementary volume of saturated cracked soil. Canadian Geotechnical Journal, 46(8), 928-942. DOI 10.1139/T09-037.

32. Kishné, A. S., Morgan, C. L., Miller, W. L. (2009). Vertisol crack extent associated with gilgai and soil moisture in the Texas Gulf Coast Prairie. Soil Science Society of America Journal, 73(4), 1221-1230. DOI 10.2136/sssaj2008.0081.

33. Zhao, X. S., Wang, Z. Y., Chen, K. S., Yang, Q. J. (2020). Measurement and calculation of fissure area and density for shrinkage soil. Earth and Environmental Science, 560, 012088. DOI 10.1088/1755.

34. Carroll, D. (1959). Ion exchange in clays and other minerals. GSA Bulletin, 70(6), 749-779. DOI 10.1130/0016.

35. Vasil'ev, N. G., O'vcharenko, F. D. (1977). The chemistry of the surfaces of the acid forms of natural layer silicates. Russian Chemical Reviews, 46(8), 775-788. DOI 10.1070/RC1977v046n08ABEH002172.

36. Meunier, A., Lanson, B., Velde, B. (2004). Composition variation of illite-vermiculite smectite mixed-layer minerals in a bentonite bed from Charente. Clay Minerals, 39(3), 317-332. DOI 10.1180/0009855043930137.

37. Yakovleva, A. A., Tu, V. D. (2012). Ion exchange on clay minerals from some deposits of Irkutsk region. Russian Journal of Applied Chemistry, 85(3), 348-351. DOI 10.1134/S1070427212030044.

38. Ministry of Railways of the People's Republic of China (2016). Code for design of railway earth structure (TB 10001-2016). China Railway Publishing House, Beijing, China. 